\title{
Obstetric Brachial Plexus Palsy
}

\author{
Treatment Strategy, Long-Term Results, and Prognosis
}

\author{
Jörg Bahm, Claudia Ocampo-Pavez, Catherine Disselhorst-Klug, \\ Bernd Sellhaus, Joachim Weis
}

\begin{abstract}
SUMMARY
Background: Obstetric brachial plexus palsy is rare, but the limb impairments are manifold and often long-lasting. Physiotherapy, microsurgical nerve reconstruction, secondary joint corrections, and muscle transpositions are employed with success. The role of conservative and operative treatment options should be regularly reviewed.

Methods: Selective literature review (evidence levels 3 and 4) and analysis of personal clinical operative and scientific experience over the past 15 years.
\end{abstract}

Results: Children with upper and total plexus palsy displaying nerve root avulsions and/or -ruptures are treated today by early primary nerve reconstruction in the first few months of life followed by secondary corrections, with good functional results. The late complications, with muscle weakness, impaired motion patterns, and joint dysplasia, are often underrated.

Conclusions: The potential for scientific analysis is limited, due to the rarity and interindividual variability of the lesions and the varying effects on function and growth. Expectations and compliance are different in every patient. Surgical techniques are not yet standardized. Knowledge of the consequences for joint growth and congruence is inadequate. Today, functional improvement can be achieved by surgery in most clinical manifestations of obstetric brachial plexus palsy, within the framework of an interdisciplinary treatment concept.

Dtsch Arztebl Int 2009; 106(6): 83-90

DOI: 10.3238/arztebl.2009.0083

Key words: obstetrics, trauma, microsurgery, neurosurgery, nerve lesion

Arbeitsbereich Plastische und Handchirurgie, Franziskushospital Aachen: Dr. med. Bahm, Dr. med. Ocampo-Pavez

Biophysikalische Messtechnik, Helmholtz Institut für Biomedizinische TechnoIogien, RWTH Aachen: PD Dr. rer. nat. Disselhorst-Klug

Institut für Neuropathologie, Universitätsklinikum der RWTH Aachen: Dr. med. Sellhaus, Prof. Dr. med. Weis
T here are no current clinical guidelines regarding obstetric brachial plexus palsy. In this article, therefore, the authors present the current state of knowledge in this area in the light of their own 15 years of specialized experience $(1,2)$, during which they treated more than 1000 children. Further sources of information for this article were a selective and up-to-date review of the literature, input from neurosurgeons $(3,4)$, and insights gained from international conferences on the subject.

\section{Introduction}

Obstetric brachial plexus palsy is a rare but sometimes very serious complication of defined high-risk deliveries. Severe nerve injuries are generally treated by early microsurgical nerve repair (8, e1). Functional restrictions and growth impairment occurring as the child grows are treated either conservatively or operatively (5). Late complications (6) are frequent and merit special attention.

\section{Clinical features and treatment strategy}

Obstetrical brachial plexus palsy occurs at a frequency of 0.38 to 1.56 per 1000 deliveries (e2) and has not become any less common despite full awareness of the problem and improved obstetrical techniques. The risk factors are shoulder dystocia (7), macrosomia (birth weight over $4 \mathrm{~kg}$ ), fetal-maternal disproportion with a narrow birth canal and/or maternal overweight (particularly in diabetes mellitus or gestational diabetes), and breech delivery.

Obstetrical brachial plexus palsies are divided into two major types according to the distribution and severity of the injury: upper brachial plexus palsy ("Erb's palsy"), involving the C5 and C6 nerve roots and sometimes $\mathrm{C} 7$ as well, and complete brachial plexus palsy, involving all of the nerve roots from $\mathrm{C} 5$ to $\mathrm{T} 1$.

Depending on the distractive force between the head and the shoulder, the plexus injury may consist solely of nerve stretching (neurapraxia), which resolves without any further deficit within three weeks, or of more severe forms ranging all the way to nerve root avulsion or proximal nerve tears, which have no potential for spontaneous recovery. The severity of the injury and the extent of paralysis are prognostically assessed in the first three to nine months of life $(1,8,9)$.

In upper brachial palsy (C5 and C6 nerve roots: shoulder muscles and forearm flexors), the shoulder is 
Figure 1:

The typical clinical appearance of a complete lesion, with a flaccid left arm and Horner's sign on the left side.

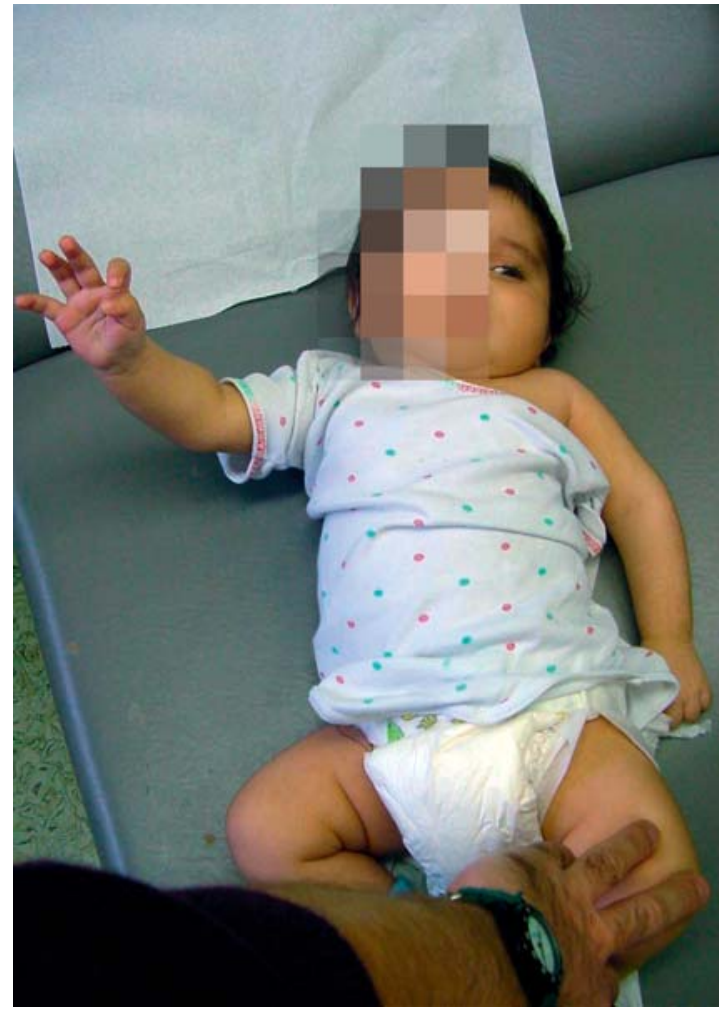

held in an adducted, internally rotated position, while the lower arm is extended and hand function remains normal. If the $\mathrm{C} 7$ nerve root is also involved, there is additional weakness of the triceps and wrist extensor muscles. In complete brachial plexus palsy, the motor and sensory function of the hand is also affected (figure 1).

In the first ten days post partum, mechanical stress is taken off the injured area of the neck by positioning the arm next to the upper body with the elbow flexed. Afterward, physiotherapy is begun, in order to support regenerative processes.

If the recovery is not yet complete by the time the infant is two months old, surgical consultation is obtained. In cases of severe injury with nerve root avulsion and/or complete brachial plexus palsy with hand involvement, surgery is performed at the age of three months. Partial upper brachial plexus palsies can be observed for further recovery for a variable period of time (till the infant is three to nine months old); inadequate regeneration of the proximal musculature (shoulder and/or biceps) signifies that microsurgical reconstruction is indicated $(1,9,10, \mathrm{e} 3)$.

Injuries of the suprascapular nerve (external rotation of the shoulder) are a special case: surgical reconstruction of this nerve is preferred in order to maintain the balance between internally and externally rotating forces about the shoulder joint, which is important for the normal development of the joint (e4, e5).

The precise indications for nerve reconstruction based on clinical scoring (with the Gilbert or Clarke

\section{BOX 1}

\section{Strength grading in children with brachial plexus injury, according to Gilbert (e31)}
M0 No contraction
M1 Contraction with movement
M2 Movement with gravity eliminated
M3 Full movement against gravity

\section{BOX 2}

\section{The Hospital for Sick Children (Clarke and Curtis) scoring system (e30)}

$\begin{array}{ll}\text { With gravity eliminated: } & \\ \text { No contraction } & 0 \\ \text { Contraction without movement } & 1 \\ \text { Movement }<1 / 2 \text { of ROM } & 2 \\ \text { Movement }>1 / 2 \text { of ROM } & 3 \\ \text { Full movement } & 4 \\ \text { Against gravity: } & \\ \text { Movement }<1 / 2 \text { of ROM } & 5 \\ \text { Movement }>1 / 2 \text { of ROM } & 6 \\ \text { Full movement } & 7\end{array}$

ROM, range of motion

scales, see boxes 1 and 2) are still a matter of debate among experts.

Electrophysiological studies may enable a prognostic statement $(\mathrm{e} 6, \mathrm{e} 7)$ in cases of neuromatous lesions with partial recovery.

Neuroimaging of the brachial plexus is not yet sophisticated enough to reveal neural rupture or neuromas. Transverse and coronal sections in magnetic resonance imaging (MRI) or post-myelographic computerized tomography (CT) can objectively demonstrate nerve root avulsion, thereby providing an argument in favor of surgery (11).

\section{Primary plexus reconstruction (12)}

The plexus is exposed under the anterior scalene muscle through a supraclavicular approach under general anesthesia (figures $2 a$ and $b$ ). The nerve trunks and roots are isolated and stimulated with electric current, and neuromatous tissue is excised. After neuropathological examination of the stumps (13), the plexus is repaired by intraplexal bridging and/or by extraplexal nerve transfers involving portions of the accessory nerve, intercostal nerves, or uninjured forearm nerves from which functionally expendable motor fascicles can be derived (14). The sural nerves are used as donor sites for nerve transplants. 
Postoperatively, the reconstruction site must be immobilized for three weeks by means of a head-and-neck cast (for a sample result, see figures $3 a$ and $3 b$ ).

\section{Further measures during initial treatment Physiotherapy}

Regular physiotherapeutic exercises based on neurophysiological principles (Vojta, Bobath, "forced use") have not been shown to be effective, but should nevertheless be ordered for all affected children for six months, and for two to three years in children who have undergone surgery or have a severe palsy. The catalogue of treatments that are reimbursable by the statutory health insurance carriers in Germany (Heilmittel-Richtlinien, Part II, Maßnahmen der physikalischen Therapie [Physical Therapy Measures], dated 16 March 2004) provides for no more than 30 physiotherapeutic sessions to treat peripheral nerve injuries, including plexus palsy; a greater number than this must be prescribed as a special exception. Severe plexus palsies with nerve-root avulsion and spinal cord injury are central nervous lesions that can be treated with neurophysiologically based physiotherapy for longer times under the provisions for CNS injuries.

Older children can also benefit from ergotherapy and specifically directed muscle build up exercises after muscle transfer procedures.

In all affected children, close attention should be paid to the free mobility and congruence of the joint.

\section{Botulinum toxin application (15)}

If simultaneous contraction of agonist and antagonist muscles has been objectively demonstrated, a target muscle (mainly the triceps, subscapularis, or teres major muscle) can be put to rest for six months by reversible blockade of its motor endplates through the intramuscular injection of botulinum toxin. A single administration usually suffices.

\section{Early secondary procedure in case of internal rotation deformity of the shoulder}

In the developing child, an imbalance between agonist and antagonist muscles not only impairs normal movement but also leads to deformities of the bones and joints. The most common abnormality of this kind affects the glenohumeral joint and the shoulder girdle $(16,17)$. Upper brachial plexus palsy often causes an imbalance at the shoulder between the few, lastingly paralyzed external rotators (injury to the suprascapular nerve) and the strong group of internal rotators. The result is a dorsal subluxation of the humeral head with an internal rotation deformity of the shoulder, sometimes with increased retroversion of the humeral head and adaptive changes of the glenoid (glenohumeral dysplasia) (18).

The internal rotation deformity of the shoulder must be looked for early on; passive stretching exercises in external rotation promote restoration of equilibrium. In case this treatment has not yielded adequate results by the age of 18 months, or if there is a postpartal subluxa-

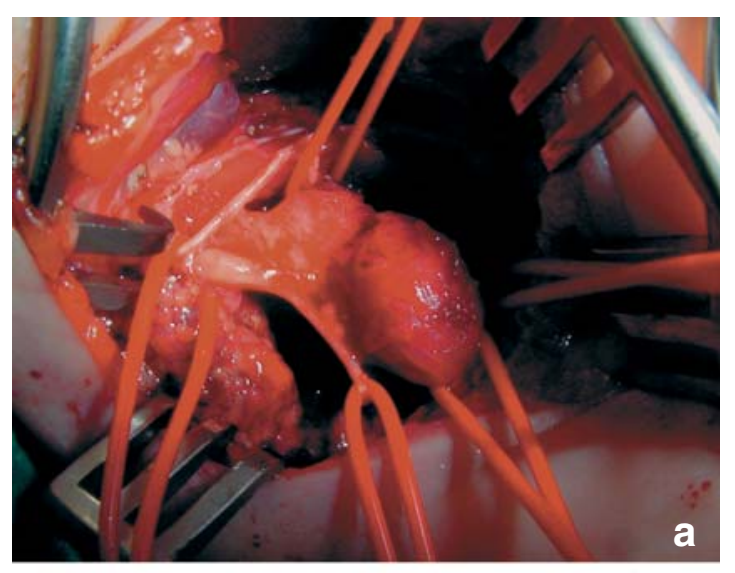

Figure 2:

(a) Intraoperative photograph of an upper lesion with a conglomerate neuroma of the upper and middle trunks of the brachial plexus. (b) Drawing of the operative findings.

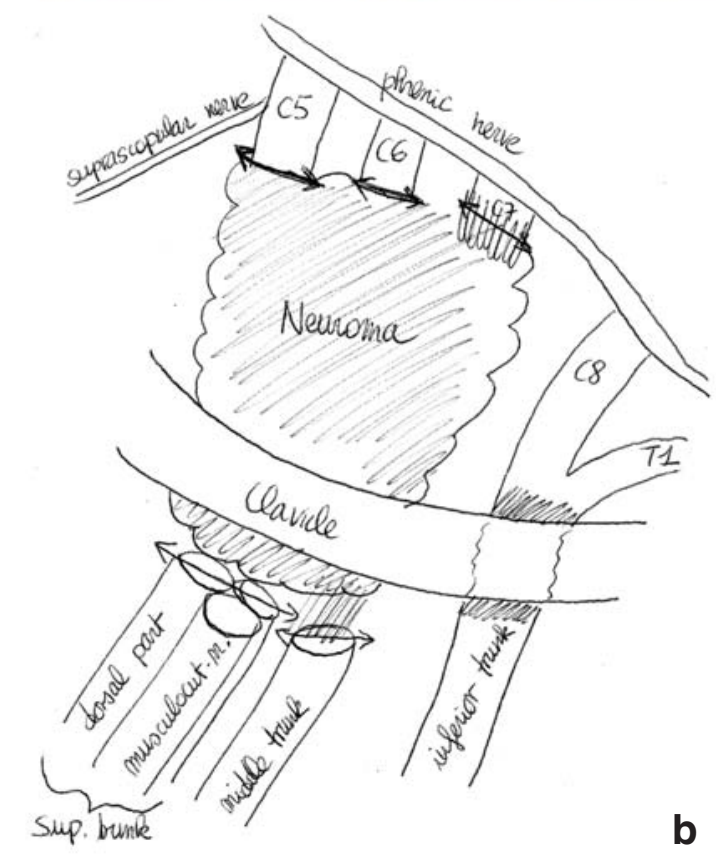

b

tion of the humeral head that has remained refractory to treatment, then open repositioning of the joint is necessary, often with partial shortening of the coracoid and lengthening of the subscapularis tendon (16).

This shoulder deformity, if present, leads to a characteristic, abnormal pattern of movement of the upper limb (increased pronation of the forearm along with restricted abduction and elbow flexion) and to a permanent disturbance of joint growth. It must, therefore, be treated early.

In severe dysfunction of the C5 nerve root, which supplies all of the muscles that stabilize the scapula, a so-called SHEAR deformity of the shoulder girdle results: Scapular Hypoplasia, Elevation, and Anterior Rotation. This can be objectively documented with three-dimensional computerized tomography (17).

Further joint changes involve the elbow (anterior luxation of the radial head, restricted extension, shrinking of the interosseous membrane leading to supination contracture) and the metacarpophalangeal joints of the 

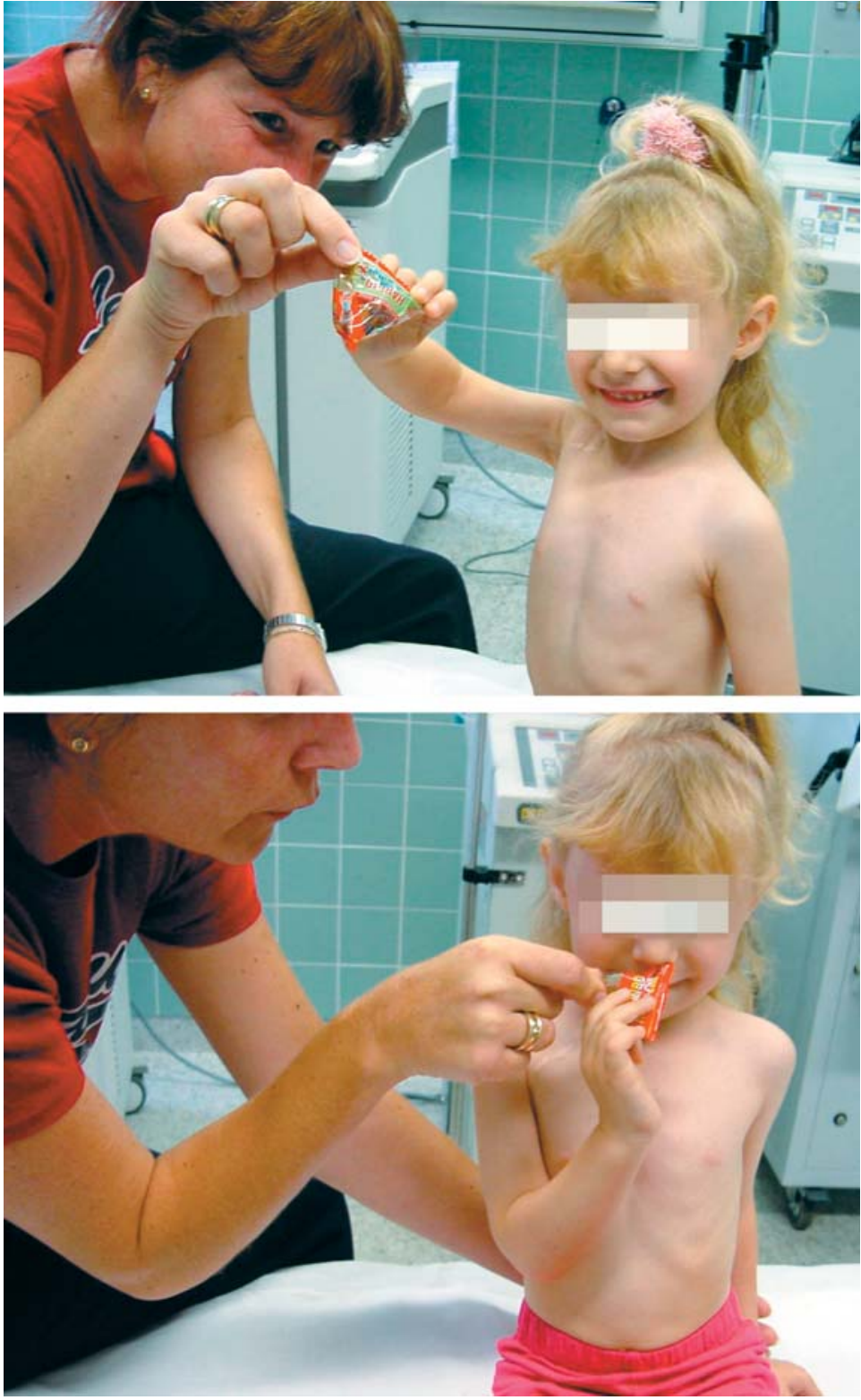

Figure 3: Result after primary reconstruction in a case of $\mathrm{C} 5$ and $\mathrm{C} 6$ nerve root avulsion during a breech delivery; (a) shoulder abduction/flexion; (b) elbow flexion (hand to mouth). 2nd through 5th fingers (intrinsic minus posture, also called the claw hand deformity).

Appropriate treatment of the luxated radial head involves repositioning, ulnar osteotomy, and ligamentous reinforcement (e8).

\section{Secondary tendon and muscle transfers}

Important target functions can be substantially improved by well-reinnervated donor muscles:

- Transposition of the flexor carpi ulnaris (FCU) tendon to activate extension of the wrist or fingers (onto the extensor carpi radialis brevis [ECRB] or extensor digitorum communis [EDC], respectively) at age 3 years, in order to correct the hand-drop posture and the associated impaired grip (2)

- Correction of the abnormally supinated posture of the lower arm by rerouting of the biceps or brachioradialis tendon (e9), release of the interosseous membrane, and correction osteotomy of the radial shaft (e10)

- Improvement of biceps or triceps function by local muscle augmentation

- Improvement of shoulder function by muscle transfer for abduction (teres major, cranial portion of trapezius, or pectoralis major) and external rotation (teres major and latissimus dorsi) (19, 20, 21, e11, e12).

\section{Late microsurgical procedures}

When the nerve supply of the arm, and especially that of the hand, is very poor after a plexus palsy has been inadequately treated or not treated at all, late reconstructive procedures may be an option:

- Restoration of minimal sensation to the hand through neurotization of the median nerve with sensory intercostal nerves (intercostobrachial n.),

- Restoration of global finger flexion through a free gracilis muscle transfer on its neurovascular pedicle into the anterior compartment of the lower arm $(\mathrm{e} 13, \mathrm{e} 14)$

\section{Methods of examination}

In small children, repeated observation and measurement of the active and passive range of motion (ROM) with description of the pattern of movement has proved to be the best method of examination. Depending on the child's age, strength is rated either on the British Medical Research Council (MRC) scale (box 3) or on the Gilbert scale (box 1).

After nerve reconstruction, the patient should be examined with attention to the degree to which the important functional goals have been attained (active abduction/antepulsion of the shoulder up to $90^{\circ}$, biceps activity with hand-to-mouth movement, finger grip); after elective muscle transfer, one should note whether the active ROM and strength (MRC M3 or above) have improved.

In a ten-year scientific cooperation with the Helmholtz Institute for Biomedical Technologies of the RWTH Aachen (Biophysical Measurement Technology), 
the authors performed painless, high-resolution surface electromyography (EMG) in children with plexus palsy in order to test particular target muscles (biceps and subscapularis) (e15). We studied co-contractions and rotatory movements of the shoulder joint with video movement analysis (e3). A dynamic EMG of the segment-indicating muscles was also recorded, and the joint strengths were calculated.

\section{Evaluation of results}

A detailed analysis after a procedure intended to improve function can only be performed on an individual basis. The utility of nerve reconstruction $(1, \mathrm{e} 3)$ depends on the extent and severity of the neural injury and on the details of the microsurgical reconstruction (number of nerve roots available, tissue quality, number of grafts and neurotizations). Successful neurotization of the inferior trunk for the restoration of hand function (e16) and recovery of the suprascapular nerve (e5) are two prominent examples.

Global results on secondary procedures have been published (2). The assignment of scores is often problematic. Mallet (20), for example, classifies patients into three groups with respect to active shoulder function (figure 4). Yet how should one classify a child with good abduction (IV), limited external rotation (II), and adequate internal rotation (III) - is the child in group II, III, or IV?

A successful treatment strategy of internal rotation contractures of the shoulder (18) is very important and leads to an improved posture in external rotation (21, e17).

\section{Discussion}

\section{Scientific-clinical observation}

Limb movements in children are hard to observe and even harder to measure according to valid scientific criteria. Small children are often unpredictably moody and uncooperative when seen in the doctor's office. The extent of movement varies depending on the examiner and the moment of examination. The scoring systems (Mallet, Gilbert, Curtis-Clarke) and locally oriented outcome scales (shoulder according to Gilbert, hand according to Raimondi [22]) (table) are of only limited informative value and tend to obscure the differences between different situations by rating them equally. Initial reports have now been published on global clinical assessment with measurement techniques that have been validated for use in children, such as the PEDI (Pediatric Evaluation of Disability Inventory) (e18) and the AHA (Assisting Hand Assessment) (e16, e19).

\section{Current literature}

Publications on evidence levels 3 and 4 can be found, including: outcome studies on daily activities in children treated surgically and conservatively and assessed with the AHA (e16), which has now been validated for plexus palsy (e19); outcome analyses for partial aspects of surgical treatment; theoretical studies on neuroplasticity

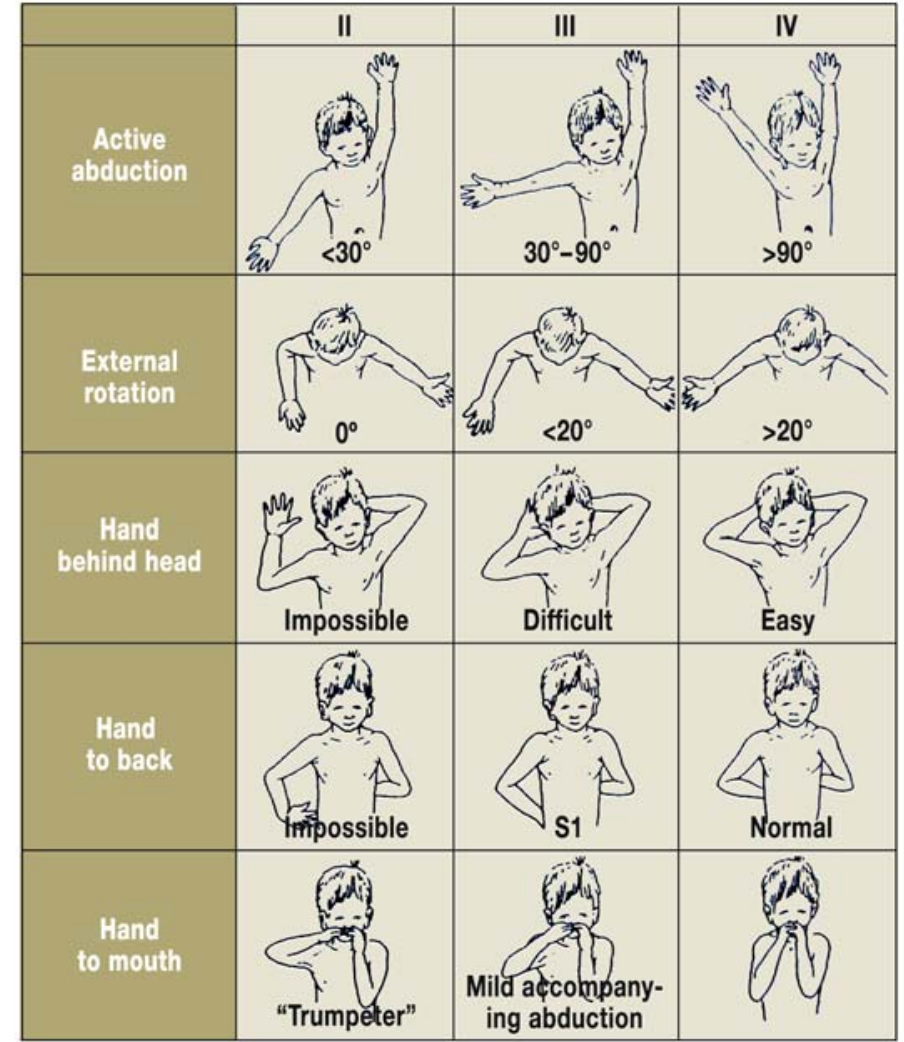

The Mallet scheme for shoulder movements.

and sensorimotor apraxia after severe plexus palsy (e20, e21) and obstetrical studies (pathogenesis, medicolegal aspects). The reality of chronically impaired function without any prospect of improvement $(5,6)$ compels us to adopt new attitudes toward prognosis and long-term physiotherapy.

\section{Some important current opportunities for improved treatment:}

- New corrective procedures: correction of abnormal supination of the lower arm by brachioradialis tendon transfer (e9)

- Technical details for improving muscle transfer to achieve active external rotation of the shoulder: selection of the individual surgical steps (e12) and of the nature and manner of attachment of the transferred muscles. Pagnotta et al. (21) provide longterm results in 203 children of muscle transfer as described by Hoffer et al. (19): in all types of paresis, active external rotation was significantly improved ("upgrading" of the Gilbert shoulder score [table]). The stabilizing effect on glenohumeral dysplasia remains unclear (23)

- Overarching principles of cerebral integration that point to limitations in the developing brain's 


\section{TABLE}

\section{Typical outcome scales:}

\begin{tabular}{l|l|} 
Degree & Function \\
\hline \multicolumn{2}{|l|}{ The Gilbert shoulder score for abduction and external rotation (21) } \\
\hline 0 & Flaccid shoulder \\
1 & Abduction to $45^{\circ}$, no active ER \\
2 & Abduction to $<90^{\circ}$, no active ER \\
3 & Abduction to $90^{\circ}$, weak active ER \\
4 & Abduction to $<120^{\circ}$, weak active ER \\
5 & Abduction to $>120^{\circ}$, complete active ER
\end{tabular}

The Raimondi score for hand function (22)

$0 \quad$ Complete paralysis or functionally useless finger flexion Non-usable thumb without grasping function Little or no sensation

Limited finger flexion

No finger or wrist extension

Key grip possible

Active wrist extension and use of the tenodesis effect Passive key grip in pronation

Complete active finger and wrist flexion

Active thumb movement, including abduction and opposition Intrinsic equilibrium No active supination (Good opportunity for surgical correction)

4 Complete active finger and wrist flexion Active wrist extension, but weak finger extension (or none) Good opposition of the thumb with active ulnar intrinsic muscles Beginning pronation and supination like 4 with active finger extension and nearly complete pronation and supination

Figure 5: Preventable late sequela: abnormal adaptive posture

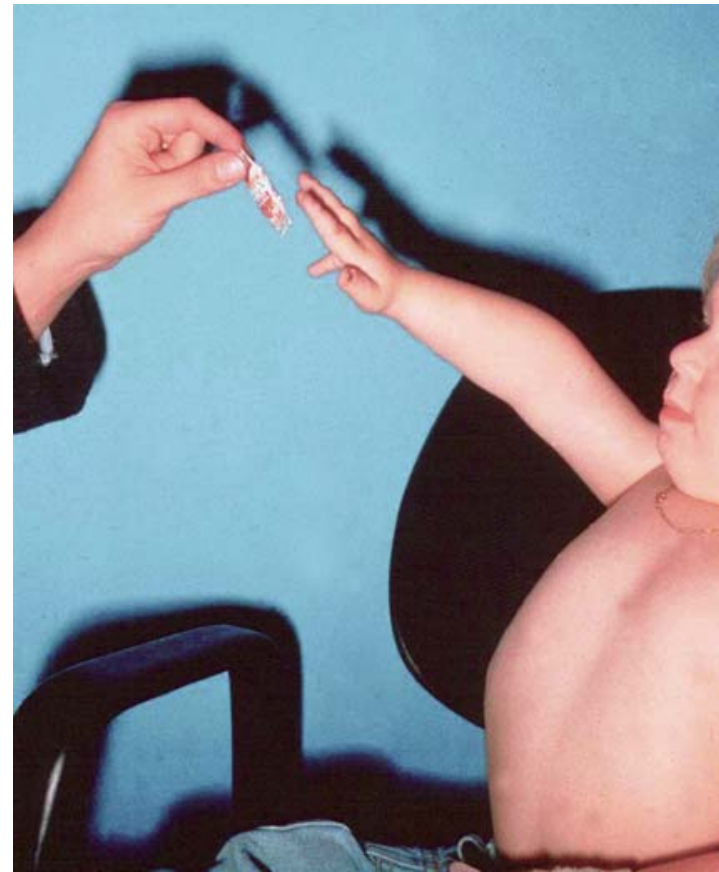

processing capacity for restrictions of movement (e20, e21, e22)

- Recovery of sensation: measured with filaments in the Semmes-Weinstein test (e23), with global functional testing (e16, e19) with particular attention to the hand (e24).

\section{Conservative versus operative treatment}

As recently as 10 years ago, this issue was hotly debated among pediatricians and physiotherapists. Mutual understanding has since come about through publications, lectures, and visits to the operating room. Moreover, microsurgical brachial plexus reconstruction has proved its value. In 2005, Birch presented the results of 100 operations performed from 1990 to 1999 (24), with a median follow-up interval of 85 months (range, 30 to 152 months). A total of 237 roots were neurotized, with the following percentages of good results: $\mathrm{C} 5,33 \%$; 6 , 55\%; C7, 24\%; C8 and T1, 57\%. In 2006, Gilbert published the long-term postoperative results in 1000 children (8). With respect to the shoulder, $80 \%$ of children with an upper lesion achieved a good or very good result by 4 years after surgery. When $\mathrm{C} 7$ was also involved, this percentage was somewhat lower $(61 \%)$. Among the complete lesions, $77 \%$ showed moderately good, good, or very good results 8 years after surgery. The results at the elbow were described as good: here, $81 \%$ of the children with complete lesions had a good or very good result 8 years after surgery. In the hand, useful function was seen in $35 \%$ after 2 years. When tendon transfer was performed, there was useful hand function in $76 \%$ of cases after 8 years.

\section{The role of neuropathology}

Systematic neuropathological quick sections of the proximal and distal nerve stumps have been found to be a very useful method of evaluating fascicle quality during reconstructive surgery for peripheral nerve injuries (hematoxylin-eosin and trichrome staining in frozen sections, toluidine blue staining in semithin sections) $(1,13)$. Furthermore, the regenerative potential of a nerve graft can be tested before a free muscle flap is attached (e13, e25).

\section{Late sequelae}

Shoulder and elbow deformities pose major problems. They are often overlooked and cause painful arthrosis in adults (16).

Scoliosis is often said to be a possible late sequela of brachial plexus injury, yet we did not encounter any instances of this among the many patients that we treated.

The effects on psychosocial functioning remain unknown. Early treatment is said to prevent the development of habitual adaptive posturing involving bizarre movements of the upper body (figure 4).

\section{Prognosis}

It has been falsely assumed that no more than $10 \%$ of all obstetrical brachial plexus palsies will fail to recover fully with conservative treatment and will therefore require surgery. 
When intraoperative inspection reveals severe injury to the nerve roots and nerve trunks, the extent of the damage and the impossibility of regeneration of avulsed or fibrosed neural tissue become evident. In such cases, normal function cannot be restored even with extensive microsurgical nerve reconstruction.

In growing children, the key elements of the pathological state, aside from muscle weakness, are abnormal growth and lack of cortical integration of the affected limb.

Handedness is determined by cerebral hemispheric dominance but can also be affected by a brachial plexus injury, depending on the neural feedback coming from the affected hand. If this hand is not up to the tasks placed on it, including writing, then the other, originally nondominant hand will take over these functions.

There has not yet been any study of the effect on body image and self-confidence during puberty, on the misjudgment of athletic "performance" in school sports, or on decisions made regarding the choice of occupation.

It is highly fortunate and scientifically remarkable that neuropathic pain is unknown among children with obstetrical brachial plexus palsy, even in their later life as adults.

\section{Medicolegal aspects}

The brachial plexus surgeon should not express any judgment regarding the delivery of the baby, but must describe the operative field and recognize the pathological evidence of nerve traction (scarring, delocalization of topographical landmarks). Plexus surgeons can also exert a beneficial influence in the prevention of this condition, along with obstetricians, who have performed both clinical and experimental studies of the internal and external forces involved in delivery (e26, e27, e28) compared to those that cause neural injury (25) and have

\section{Key messages}

- Severe upper or complete obstetrical brachial plexus palsies must be operated on early.

- Because of the possibility of multiple late sequelae affecting the function and growth of the limb, clinical follow-up should be performed at close intervals and for a long time, and patients should be treated with physiotherapy and corrective procedures if necessary.

- Internal rotation deformity of the shoulder is a frequently overlooked complication of the muscular imbalance caused by Erb's palsy.

- Secondary joint deformities of the shoulder and elbow have been inadequately studied, and the opportunity to treat them is limited.

- Not enough attention has been paid to the effects of obstetrical brachial plexus palsy on the everyday life of the affected child and (later) adult. Only early, intensive treatment can prevent late sequelae. described the proper management of shoulder dystocia (7, e28).

Controversy remains on the question whether the tractile forces applied externally by the obstetrician are superior to the expulsive force of the uterus, and how a peripartal plexus palsy can arise when no pathological tractile force is exerted during normal delivery. Anatomical variants such as a cervical rib can cause traction on neural tissue through a pulley-like effect, thereby aggravating traction injury on the nerve roots (e29).

\section{Conflict of interest statement}

The authors state that they have no conflict of interest as defined by the guidelines of the International Committee of Medical Journal Editors.

Manuscript submitted on 14 January 2008, revised version accepted on 1 September 2008.

Translated from the original German by Ethan Taub, M.D.

\section{REFERENCES}

1. Bahm J: Die kindliche Armplexusparese-Übersicht zur Klinik, Pathophysiologie und chirurgischen Behandlungsstrategie. Handchir Mikrochir Plast Chir 2003; 35: 83-97.

2. Bahm J: Die kindliche Armplexusparese-Eine aktuelle Übersicht sekundärer Operationsverfahren. Handchir Mikrochir Plast Chir 2004; 36: 37-46.

3. Antoniadis G, König RW, Mohr K, Kretschmer T, Richter HP: Management bei geburtstraumatischen Läsionen des Plexus brachialis-Eigene Erfahrungen mit der primären operativen Behandlung. Handchir Mikrochir Plast Chir 2003; 35: 98-105.

4. Heilmann A, Krishnan KG, Heubner G, Pinzer Th, Schackert G, Gahr M: Therapeutisches Vorgehen bei geburtstraumatischer Plexus-brachialis-Läsion. Ärzteblatt Sachsen 2003; 9: 423-6.

5. Strömbeck C, Krumlinde-Sundholm L, Remahl S, Sejersen T: Long-term follow-up of children with obstetric brachial plexus palsy I: functional aspects. Dev Med Child Neurol 2007; 49: 198-203.

6. Soucacos PN, Vekris MD, Zoubos AB, Johnson EO: Secondary reanimation procedures in late obstetrical brachial plexus palsy patients. Microsurg 2006; 26: 343-51.

7. Krause M, Feige A: GebFra-Refresher Schulterdystokie. Geburtsh und Frauenheilk 2002; 62: R221-40.

8. Gilbert A, Pivato G, Kheiralla T: Long-term results of primary repair of brachial plexus lesions in children. Microsurg 2006; 26: 334-42.

9. Marcus JR, Clarke HM: Management of obstetrical brachial plexus palsy-evaluation, prognosis, and primary surgical treatment. Clin Plast Surg 2003; 30: 289-306.

10. Chuang DCC, Mardini S, Ma HS: Surgical strategy for infant obstetrical brachial plexus palsy: Experiences at Chang Gung Memorial Hospital. Plast Reconstr Surg 2005; 116: 132-42.

11. Yamazaki H, Doi K, Hattori Y, Sakamoto S: Computerized tomography myelography with a coronal and oblique coronal view for diagnosis of nerve root avulsion in brachial plexus injury. J Brachial Plex Peripher Nerve Inj 2007; 2: 16.

12. Bahm J, Ocampo-Pavez C, Noaman H: Microsurgical technique in obstetric brachial plexus repair: a personal experience in 200 cases over 10 years. J Brachial Plex Peripher Nerve Inj 2007; 2: $1-7$.

13. Becker MHJ, Ingianni G, Lassner F, Atkins D, Schröder JM: Intraoperative Schnellschnittdiagnostik bei der geburtstraumatischen Plexusläsion-Gegenüberstellung von Makroskopie, HE-Schnellschnitten und Semidünnschnitten mit Toluidinblau-Färbung. Handchir Mikrochir Plast Chir 2003; 35: 112-116. 
14. Oberlin C, Beal D, Leechavengvongs S, Salon A, Dauge MC, Sarcy $\mathrm{JJ}$ : Nerve transfer to biceps muscle using a part of ulnar nerve for C5/C6 avulsion of the brachial plexus. Anatomical study and report of 4 cases. J Hand Surg 1994; 19: 232-7.

15. DeMatteo C, Bain JR, Galea V, Gjertsen D: Botulinum toxin as an adjunct to motor learning therapy and surgery for obstetrical brachial plexus injury. Dev Med Child Neurol 2006; 48: 245-52.

16. Birch R: Medial rotation contracture and posterior dislocation of the shoulder. In: Gilbert A (ed): Brachial Plexus Injuries. London: Dunitz 2001.

17. Nath RK, Paizi M: Scapular deformity in obstetric brachial plexus palsy: a new finding. Surg Radiol Anat 2007; 29: 133-40.

18. Bahm J, Wein B, Alhares G, Dogan C, Radermacher K, Schuind F: Assessment and treatment of glenohumeral joint deformities in children suffering from obstetric brachial plexus palsy. J Pediatr Orthop 2007; 16B: 243-51.

19. Hoffer MM, Wickenden R, Roper B: Brachial plexus birth palsies: Results of tendon transfer to the rotator cuff. J Bone Joint Surg 1978; 60A: 691-5.

20. Mallet J: Obstetrical paralysis of the brachial plexus. B. Treatment of secondary deformities. Principles of treatment of the shoulder. Classification of Results. Rev Chir Orthop 1972; 58 (Suppl1): 166-8.
21. Pagnotta A, Haerle M, Gilbert A: Long-term results on abduction and external rotation of the shoulder after latissimus dorsi transfer for sequelae of obstetric palsy. Clin Orthop Relat R 2004; 426: 199-205.

22. Raimondi P: Evaluation of results in obstetric brachial plexus palsy: the hand. Presented at the International Meeting on Obstetric Brachial Plexus Palsy. Heerlen, The Netherlands, 1993.

23. Waters PM, Bae DS: Effect of tendon transfers and extra-articular soft-tissue balancing on glenohumeral development in brachial plexus birth palsy. J Bone Joint Surg 2005; 87A: 320-5.

24. Birch R, Ahad N, Kono H, Smith S: Repair of obstetric brachial plexus palsy: results in 100 children. J Bone Joint Surg 2005 87B: 1089-95.

25. Metaizeau JP, Gayet C, Plenat F: Brachial plexus injuries: an experimental study. Chir Pediatr 1979; 20: 159-63.

\section{Corresponding author \\ Dr. med. Jörg Bahm \\ Franziskushospital \\ Morillenhang 27 \\ 52074 Aachen, Germany \\ jorg.bahm@belgacom.net} www.aerztblatt-international.de/ref0609 


\title{
REVIEW ARTICLE
}

\section{Obstetric Brachial Plexus Palsy}

\author{
Treatment Strategy, Long-Term Results, and Prognosis
}

\author{
Jörg Bahm, Claudia Ocampo-Pavez, Catherine Disselhorst-Klug, \\ Bernd Sellhaus, Joachim Weis
}

\section{E-REFERENCES}

e1. Van Dijk JG, Pondaag W, Malessy MJA: Obstetric lesions of the brachial plexus. Muscle Nerve 2001; 24: 1451-61.

e2. Waters PM: Update on management of pediatric brachial plexus palsy. J Pediat Orthop 2005; 14A: 233-44.

e3. Bahm J, Becker M, Disselhorst-Klug C et al.: Surgical strategy in obstetric brachial plexus palsy: the Aachen Experience. Semin Plast Surg 2004; 18: 285-99.

e4. Bahm J, Noaman H, Becker M: The dorsal approach to the suprascapular nerve in neuromuscular reanimation for obstetric brachial plexus lesions. Plast Reconstr Surg 2005; 115: 240-4.

e5. Pondaag W, de Boer R, van Wijlen-Hempel MS, Hofstede-Buitenhuis SM, Malessy MJA: External rotation as a result of suprascapular nerve neurotization in obstetric brachial plexus lesions. Neurosurgery 2005; 57: 530-7.

e6. Bisinella GL,Birch R, Smith SJM: Neurophysiological predicition of outcome in obstetric lesions of the brachial plexus. J Hand Surg 2003; 28B: 148-52.

e7. Vredeveld JW, Blaauw H, Sloof BACJ, Rozeman CAM: The findings in paediatric obstetric brachial plexus palsy differ from those in older patients: a suggested explanation. Dev Med Child Neurol 2000; 42: 158-61.

e8. Horii E, Nakamura R, Koh S, Inagaki H, Yajima H, Nakao E: Surgical treatment for chronic radial head dislocation. J Bone Joint Surg 2002; 84A: 1183-8.

e9. Ozkan T, Aydin A, Ozer K, Ozturk K, Durmaz H, Ozkan S: A surgical technique for pediatric forearm pronation: brachioradialis rerouting with interosseous membrane release. J Hand Surg 2004; 29A: 22-7.

e10. Bahm J, Gilbert A: Surgical correction of supination deformity in children with obstetric brachial plexus palsy. J Hand Surg 2002; 27B: 20-3.

e11. El Gammal TA, Saleh WR, El Sayed A, Kotb MM, Imam HM, Fathi NA: Tendon transfer around the shoulder in obstetric brachial plexus paralysis: clinical and computed tomographic study. J Pediatr Orthop 2006; 26: 641-6.

e12. Nath RK, Paizi M: Improvement in abduction of the shoulder after reconstructive soft-tissue procedures in obstetric brachial plexus palsy. J Bone Joint Surg 2007; 89B: 620-6.

e13. Bahm J, Ocampo-Pavez C: Free functional gracilis muscle transfer in obstetric brachial plexus palsy. J brachial Plex Peripher Nerve Inj 2008 (submitted).

e14. Chuang DCC: Neurotization and free muscle transfer for brachial plexus avulsion injury. Hand Clin 2007; 23: 91-104.

e15. Bahm J, Meinecke L, Brandenbusch V, Rau G, Disselhorst-Klug C: High spatial resolution electromyography and video-assisted movement analysis in children with obstetric brachial plexus palsy. Hand Clin 2003; 19: 393-9.

e16. Krumlinde-Sundholm L: Development of the Assisting Hand Assessment: a rasch-built measure intended for children with unilateral upper limb impairments. Scand J Occupational Therapy 2003; 10: 16-26. e17. Kirkos JM, Kyrkos MJ, Kapetanos GA, Haritidis JH: Brachial plexus palsy secondary to birth injuries: long-term results of anterior release and tendon transfers around the shoulder. J Bone Joint Surg 2005 ; 87B: 231-5.

e18. Ho ES, Curtis CG, Clarke HM: Pediatric evaluation of disability inventory: its application to children with obstetric brachial plexus palsy. J Hand Surg 2006; 31A: 197-202.

e19. Krumlinde-Sundholm L, Holmefur M, Kottorp A, Eliasson AC: The Assisting Hand Assessment: current evidence of validity, reliability, and responsiveness to change. Dev Med Child Neurol 2007; 49: 259-64.

e20. Noetzel MJ, Wolpaw JR: Emerging concepts in the pathophysiology of recovery from neonatal brachial plexus injury. Neurology 2000; 55: 5-6.

e21. Brown T, Cupido C, Scarfone H, Pape K, Galea V, McComas A: Developmental apraxia arising from neonatal brachial plexus palsy. Neurology 2000; 55: 24-30.

e22. Strömbeck C, Remahl S, Krumlinde-Sundholm L, Sejersen T: Longterm follow-up of children with obstetric brachial plexus palsy II: neurophysiological aspects. Dev Med Child Neurol 2007; 49: 204-9.

e23. PalmgrenT, Peltonen J, Linder T, Rautakorpi S, Nietosvaara Y: Sensory evaluation of the hands in children with brachial plexus birth injury. Dev Med Child Neurol 2007; 49: 582-6.

e24. Pondaag W, Malessy MJA: Recovery of hand function following nerve grafting and transfer in obstetric brachial plexus lesions. J Neurosurg Pediatr 2006; 105: 33-40.

e25. Hattori Y, Doi K, Dhawan V, Ikeda K, Kaneko K, Ohi R: Choline acetyltransferase activity and evoked spinal cord potentials for the diagnosis of brachial plexus injury. J Bone Joint Surg 2004; 86B: 70-3.

e26. Allen RH: On the mechanical aspects of shoulder dystocia and birth injury. Clinical Obstet Gynecol 2007; 50: 607-23.

e27. Gonik B, Walker A, Grimm M: Mathematic modeling of forces associated with shoulder dystocia: a comparison of endogenous and exogenous sources. Am J Obstet Gynecol 2000; 182: 689-91.

e28. Gurewitsch ED: Optimizing shoulder dystocia management to prevent birth injury. Clinical Obstet Gynecol 2007; 50: 592-606.

e29. Becker MHJ, Lassner F, Bahm J, Ingianni G, Pallua N: The cervical rib. a predisposing factor for obstetric brachial plexus lesions. J Bone Joint Surg 2002; 84B: 740-3.

e30. Clarke HM, Curtis CG: An approach to obstetrical brachial plexus injuries. Hand Clin 1995; 11: 563-80.

e31. Gilbert A, Tasson JL: Obstetrical palsy: a clinical, pathologic and surgical review. In: Terzis JK: Microreconstruction of nerve injuries. Philadelphia: Saunders 1987. 